\title{
An integrated decision-support process for adaptation planning: climate change as impetus for scenario planning in an agricultural region of Canada
}

\author{
Ruth Waldick $^{1,2} \cdot$ Livia Bizikova $^{3} \cdot$ Denis White $^{4} \cdot$ Kathryn Lindsay $^{5,6}$
}

Received: 21 May 2015/Accepted: 24 May 2016/Published online: 8 June 2016

(C) The Author(s) 2016. This article is published with open access at Springerlink.com

\begin{abstract}
The amount of information required to adapt to climate change is vast: downscaled climate projections, information on environmental impact, sectoral performance, external drivers, regional strategies, policies and practices. It can be argued that most of this information is accessible at the community/regional level, and thus, the important challenges to adaptation are not information gaps, but constraints created by fragmented planning decisions and a sector-by-sector basis for financial and human resource allocations. To strategically address this through adaptation planning, we developed and tested a place-based decision-making framework that creates an integrated platform for considering regional and global sectoral drivers in Eastern Ontario, Canada. Using available socioeconomic and biophysical information from regional authorities, alternative future scenarios were used
\end{abstract}

Editor: Nicolas Dendoncker.

Electronic supplementary material The online version of this article (doi:10.1007/s10113-016-0992-5) contains supplementary material, which is available to authorized users.

Ruth Waldick

ruth.waldick@agr.gc.ca; ruth.waldick@carleton.ca

Livia Bizikova

lbizikova@iisd.ca

Denis White

whitede@oregonstate.edu

Kathryn Lindsay

Kathryn.Lindsay@glel.carleton.ca

1 Agriculture and Agri-Food Canada, 960 Carling Avenue, Ottawa, ON, Canada

2 Department of Geography, Carleton University, 1100 Colonel By Drive, Ottawa, ON, Canada to describe the range of socioeconomic futures and their vulnerabilities to climate change. We found that: (1) integration of diverse sets of available data (rather than narrowly focused sectoral assessments) helped identify shared common objectives (maximizing the long-term environmental, economic, social well-being within the region), (2) a high degree of congruence existed as the key drivers of change, irrespective of sector, (3) exploring the future scenarios highlighted shared regional priorities and helped identify adaptation priorities requiring more integrated regional planning.

Keywords Climate change adaptation - Scenarios . Regional planning · Canada · Agriculture · Integrated assessment · Uncertainty

\section{Introduction}

Regional policymakers and other local stakeholders are recognized as important contributors in pro-active adaptation planning to climate change (Olesen et al. 2011; IPCC

3 International Institute for Sustainable Development (IISD), 75 Albert Street, Suite 903, Ottawa K1P 5E7, ON, Canada

4 Geography Program, College of Earth, Ocean, and Atmospheric Sciences, Oregon State University, Corvallis, OR, USA

5 Wildlife and Landscape Science, Environment Canada, National Wildlife Research Centre, Ottawa K1A 0H3, ON, Canada

6 Geomatics and Landscape Ecology Research Lab, Carleton University, Ottawa K1S 5B6, ON, Canada 
2012). However, existing governance structures present challenges to strategic planning due to mismatches between management boundaries and the biophysical boundaries at which impacts are realized (e.g., planning district vs. watershed). Moreover, differences in socioeconomic priorities and perspectives can also create conflicts in land use and on the time horizons on which operations and planning are based. A growing body of multi-disciplinary frameworks is emerging to try to address such cross-scale complexity and facilitate longer-term (strategic) planning (Verburg et al. 2004; Bolte et al. 2006; Duinker and Greig 2007). A major challenge to such frameworks is picking the appropriate scale and level of complexity to consider without excluding important factors, for example, by taking an overly narrow disciplinary scope. Risk-based approaches that consider drivers like climate change are explicitly designed to address complexity and uncertainty across scales of time and space (Thomalla et al. 2006; Anton et al. 2013), to provide a template for considering interdisciplinary perspectives, and to identify critical uncertainties. When hard data are not available, techniques that employ multi-stakeholder engagement to consider risk can provide context for how local socioeconomic systems may be affected by different types of change (IPCC 2014).

Climate change introduces an additional layer of uncertainty to land use planning. Climate models project that variation in temperature, wind, and precipitation will increase both within as well as across years (UKCIP 2011). These sorts of dynamic changes make it difficult to identify specific adaptation actions and can mean that selecting adaptations ultimately requires a decision based on some level of 'acceptable' risk (Howden et al. 2007). To be successfully adopted into land use and management plans, adaptations must also be accepted by members of the society in question; any proposed changes must reflect shared views on what are and are not acceptable levels of risk, common values, and objectives (Eriksen et al. 2011). This makes it important to include a broad range of perspectives to ensure that complex multi-sectoral trade-offs, and potential conflicts in cross-sector policy are considered (Flitcroft et al. 2011; van Buuren et al. 2014). To increase policy coherence during the planning process, engagement can explicitly aim at considering a more complete set of social, economic, and environmental determinants that will influence a region's vulnerability (Adger et al. 2005; Polasky et al. 2011) and increase the legitimacy of outcomes (Stirling 2006; Volkery et al. 2006). This is important since regionally explicit information on climate change risks and opportunities-e.g., information on changes in land price, disease or pest cycles, or resource availability (water or energy)—will not be available for all relevant areas. Planners need some way to consider such issues.
How resilient or vulnerable a region is to future climate extremes depends also on the suite of available capacities ranging from social to economic, environmental, and institutional aspects referred to also as contextual vulnerability (O'Brien et al. 2007 in IPCC 2014). The importance of integrating diverse sectoral information, stakeholders' perspectives, and existing capacities into adaptation planning is beginning to emerge in the literature. Biesbroek et al. (2011) and Bizikova et al. (2014) highlight the need for broad sectoral consultation in conjunction with scenario approaches as tools to bring together climate impact information with socioeconomic development when designing adaptation options. This approach has been demonstrated both at the national level (Finland and the Netherlands) and at community levels (Canada, Sweden, and the UK; Carter et al. 2005; Tompkins et al. 2008; Shaw et al. 2009; Carlsen et al. 2012; Harrison et al. 2013). Carlsen et al. (2012) distinguish three major roles for scenarios in adaptation planning: (1) identifying future environmental and socioeconomic challenges; (2) identifying socioeconomic changes importance to deal with climate change impacts; and (3) identifying appropriate adaptation options. In most cases, scenarios are seen as learning and capacity-building tools to improve decision-makers' understanding of the consequences of climate change (Tompkins et al. 2008; Mahmoud et al. 2009; Shaw et al. 2009; Bizikova et al., 2014). Recent applications largely focus on socioeconomic challenges relevant for climate change, such as growing population, urbanization, and demand for food (Tompkins et al. 2008; Shaw et al. 2009), changes in tourism (Carlsen et al. 2012), or policy development and governance (Harrison et al. 2013).

Presently, scenarios used in agricultural contexts have largely been developed by agricultural experts to consider impacts of climate change on crop production and yield under different climate and management scenarios (IFRI 2010; Öborn et al. 2011; Nelson et al. 2014) or by economists to evaluate the impacts of climate change and global trade on commodity prices, food prices, and global markets (Willenbockel 2011; von Lampe et al. 2014). So far, scenario approaches have not been used to a large extent to generate dialogue regarding the future of regional agriculture or to explore linkages between adaptation actions and policy development. This paper addresses these gaps by demonstrating the use of scenarios for exploring interactions between local and external driving forces based on information about stakeholders' preferences and available data, assessing potential challenges, opportunities, and adaptation needs across and within different futures with the goal of identifying strategic adaptation needs at the regional level. The relevance of using scenarios as tools to consider impacts from climate in the context of other challenges and opportunities for adaptation planning is highlighted. 
To address this focus, we designed a cyclical, multistakeholder approach that built on existing knowledge and identified areas of climate change impacts, sectorial and regional priorities and policies in a region. This framework differs from other regional planning and climate change adaptation frameworks in identifying and prioritizing key drivers of change in order to emphasize opportunities and challenges and how this will influence future vulnerability. This paper describes key elements of this futures-based framework, the results from participatory engagement, and examines levels of concordance among sectors in key drivers and adaptation needs (as well as gaps).

\section{Methodological approach}

In this study, the methodological approach aims to assist in the adaptation planning at the regional level by integrating regional and global sectoral drivers to develop a set of scenarios using available socioeconomic and biophysical information from regional authorities. Specifically, the objectives of the study are to:

- Develop a set of alternative scenarios that can consider critical drivers such as climate change, economic development, and agricultural change, and identify their impacts on the environment and well-being;

- To explore the use of scenario approaches to engage diverse stakeholders in order to identify common objectives for the region in the context of climate change;

- Assess the role of scenarios and scenario engagement in supporting a strategic approach to adaptation, specifically, by including consideration of broader regional priorities, challenges, and opportunities when prioritizing adaptation actions.

The selected area of study is Eastern Ontario, Canada. In the next section, we review the study area, current climate, and weather impacts for the area and provide an overview of our approach to the scenario development. Detailed description of the methodological approach for scenario development is provided in supplementary materials.

\section{Study area}

We selected a diversified rural landscape in which agriculture represents a significant proportion of land use and is a major contributor to regional socioeconomic systems. This large geographic area located in the southeastern region of Ontario, Canada was chosen in order to capture a mixed rural perspective on climate change adaptation planning (Fig. 1). Furthermore, the region was chosen because of potentially high contextual vulnerability to climate change that is applicable to many southern agricultural region of Canada (Anton et al. 2011), such as increasing competitiveness within the agricultural sector, aging demographics, degrading infrastructure, and different environmental challenges (i.e., water quality and management of stream and reservoir levels and flows).

The area is bounded by jurisdictional lines, representing several layers of political (i.e., county, provincial, and federal governments) and management groups (watershed Conservation Authorities, non-governmental and sectoral organizations). The region has a mixed and diverse economy that includes agriculture, forestry, mixed industry, as well as a series of national and provincial parks and recreational areas. Although the region has lost some major industry over the last number of years, the population has grown and is expected to increase from 1.3 million people (2011) to 1.7 million people by 2036, most of which is expected to take place in urban centers (Ontario Ministry of Finance 2014). The number of farms has been declining over the past three decades, although there is little net change to the farmed area, due to farm size having increased (average farm size in 2011 of 110 ha). The distribution of agricultural systems reflects weather and soil conditions within the region (Fig. 1). Soil and subsurface conditions are poor across much of the study area and where suitable lands require draining in order to be used for housing or agriculture. Presently, most of the land is in private ownership, with agriculture representing the bulk of the area (approximately $52 \%$ of the region's total land use; $8400 \mathrm{~km}^{2}$ ). Agriculture is in either crops (corn, wheat, soybean, etc.,) or pasture (natural, alfalfa, tame hay etc.,), although some cattle ranching, hay farming, oilseed, and grain production are present.

\section{Climate change considerations}

The trend observed over the past 60 years is of increasing annual air temperature. Most warming is attributable to shorter and milder winters, with longer freeze-free periods (Kharin and Zwiers 2005; Qian et al.2010a, b). However, summer heat waves (days with temperatures exceeding 30 degrees) are expected to become more frequent, doubling in occurrence between now and 2050 (Qian et al. 2010a, b).

Precipitation has also been increasing annually in this region. By 2050, this increase is projected to give rise to precipitation approximately $6 \%$ higher than the mean annual precipitation observed in the latter half of the twentieth century (1961-1990). However, the timing of precipitation events is expected to shift. Overall, net moisture availability will be adversely affected by the combined effects of warmer temperatures and increased evaporation and evapotranspiration rates (Chiotti and Lavender 2008); soil moisture may decrease by as much as 


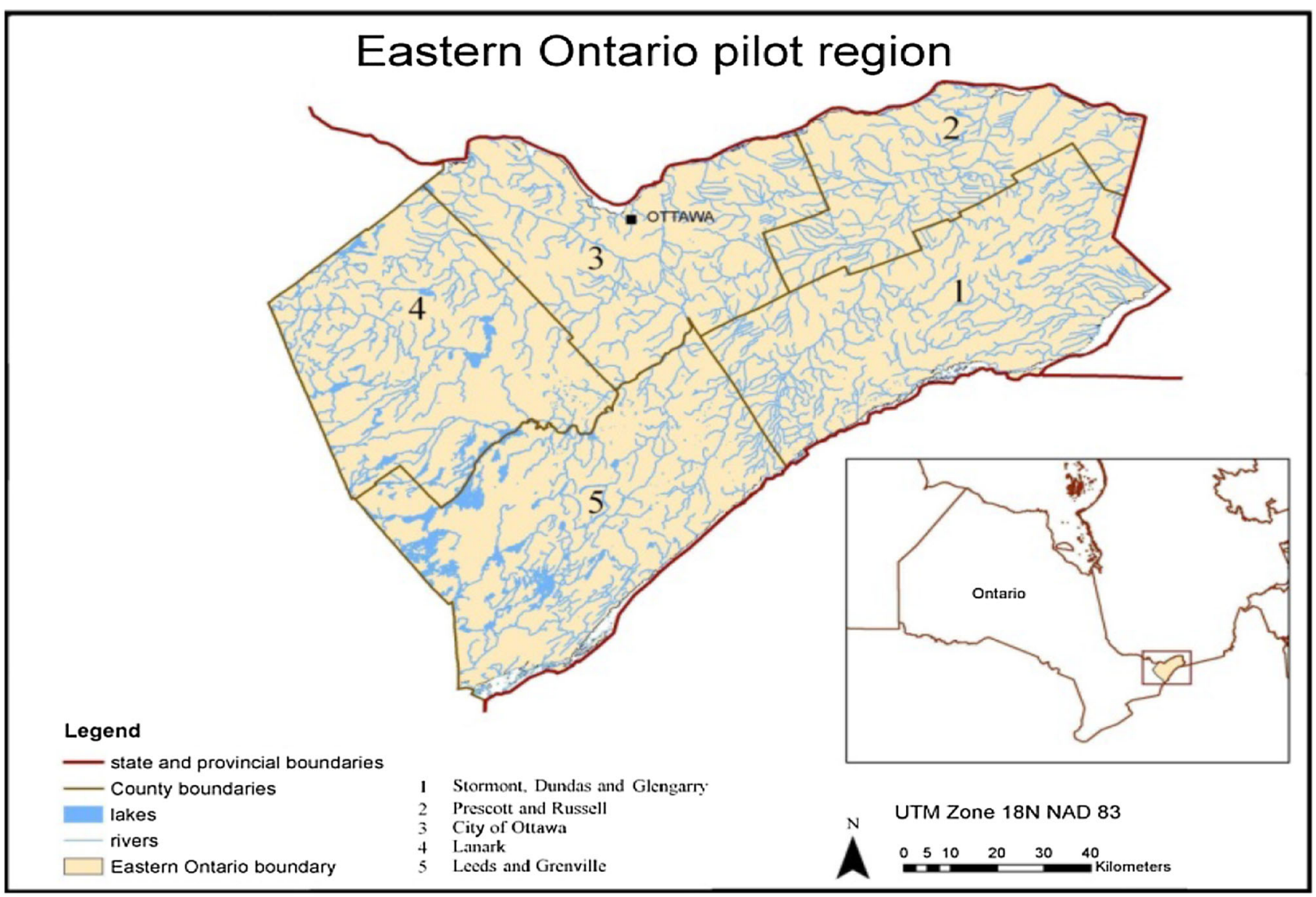

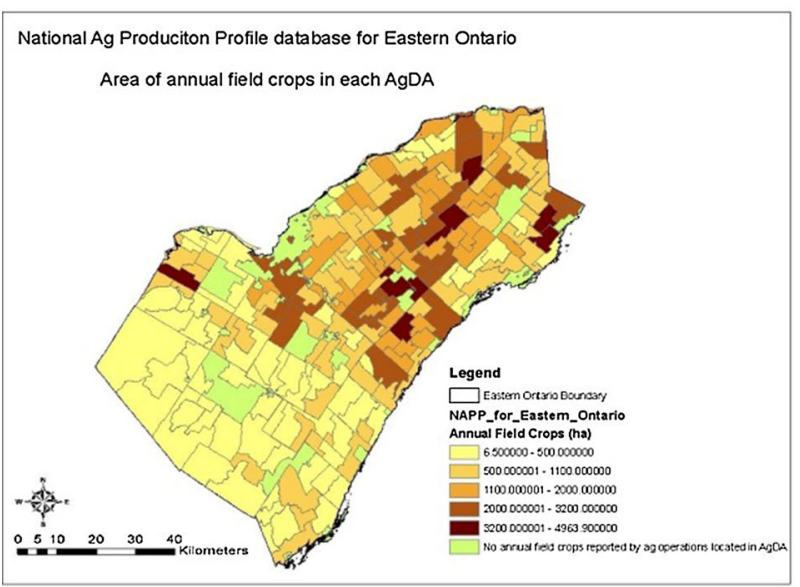

Fig. 1 Map of study region in Eastern Ontario. A total of five counties in the southeastern region of Ontario, bordering the Quebec border, were included in this study. Agricultural land use in this

$30 \%$ in the growing season. The implications of these weather changes on productivity are unclear, whereas warmer temperatures are expected to contribute to a significant lengthening of the growing season in this region with earlier crop seeding dates and later fall frost dates; localized extreme weather such as heavy precipitation, drought, late spring frost, and freezing rain, is expected to

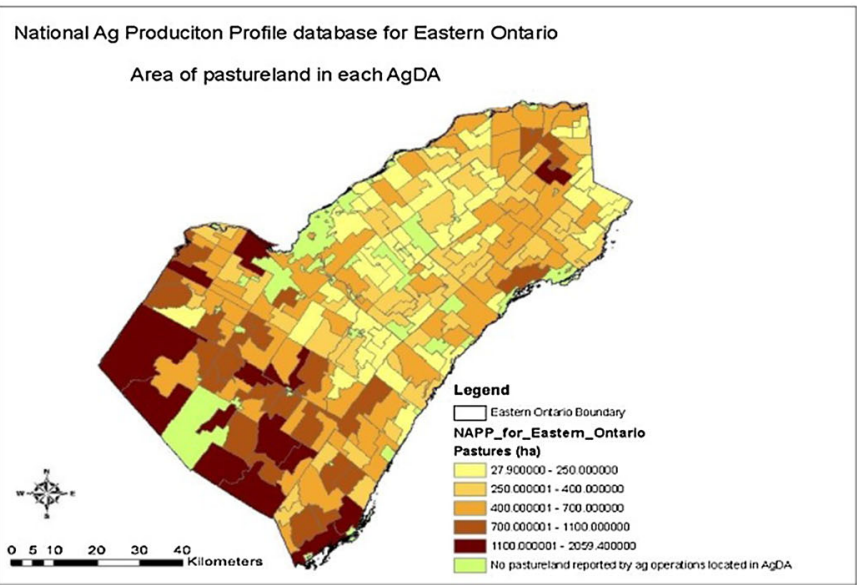

region is divided into two main categories: field crops (lower left map) and pastureland with associated livestock industry (lower right map)

result in fluctuations in annual yields independent of growing season length. This is expected to occur even in the absence of large-scale catastrophic events; both increased day-to-day and seasonal fluctuations in temperature and precipitation which are expected to reduce growth and yields through risks that may be considered manageable (e.g., increased risks from pests, diseases, 
weeds, and to some extent drought) as well as those falling outside of range of existing coping strategies (e.g., heat extreme impacts on water availability; physical damage to crops from freezing rain/hailstorms; Rochette et al. 2004; Fisher et al. 2012; Anton et al. 2013; Seo 2013; Burke et al. 2015; Yusa et al. 2015).

The economic impacts of extreme weather and changing climate may be particularly great when sequential lowproduction years combine (Baez et al. 2013; Kulshreshtha and Wheaton 2013; Burke et al. 2015) or when such conditions are cumulative in their impact (Reid et al. 2007; Windsor Climate Change Adaptation Plan 2012). In 2012, for example, Ontario tree fruit growers experienced significant losses when an unseasonably warm spring was followed by a brief period of frost during the sensitive bloom and emerging bud period (OMAFRA 2015). The estimated costs include $\$ 114$ million in losses to the apple, cherry, plum, and peach sectors, with another $\$ 74$ million in payouts through Business Risk Management programs.

The interactions between land use and climate change are also likely to be important to natural systems. In the past several decades, wildlife habitat has been reduced in extent and quality by the growth of urban centers, which reduces both natural and agricultural habitat (Eilers et al. 2010), agricultural intensification, which reduces habitat through the loss of pasture lands, and by related changes in land management practices. Heavy precipitation events are expected to exacerbate these effects, detrimentally impacting aquatic systems and wildlife habitat through, for example, episodic release of residual soil nitrogen and other nutrients and chemicals into subsurface and surface waters. It is worth noting that corn and soybeans, which have a low habitat value compared to natural and seminatural cover, represent much of the area (Kirk et al. 2011).

\section{Scenario development framework}

The framework applied in this study includes a series of steps from identifying key drivers, scenario development to selecting adaptation actions and integrating them with planning processes (Fig. 2). Because the framework aims to bring together stakeholders to develop a set of qualitative scenarios and then quantify them, both the stakeholders' participation and access to the data and models for quantification are critical.

The initial set of stakeholders' were identified and contacted through the use of directories of local farming associations (e.g., Soil and Crop Improvement, Dairy Farmers of Canada), and direct contact with regional government offices (municipal, provincial, federal). The range was expanded through snowball sampling (Atkinson and Flint, 2001). Over the course of the study, over 80 people contributed to this work. The participants comprised of a mixture of regional expertise, supplemented as required through targeted external expert groups and supplementary interviews, to expand inputs to include further background information, sectoral or jurisdictional perspectives (e.g., national, provincial, and local authorities). Detailed overview of the stakeholders' identification approach and the list of key agencies are presented in supplementary material.

Data and information used in this study were gathered from ongoing research and a review of all accessible information, priorities, and previous work in the region. This included the published literature, governmental databases, as well as 'gray literature' reports. This information was used to understand current trends and inform participatory workshops (see supplementary materials). Data sources used as part of the framework were incorporated through one of two parallel activities: quantitative modeling by analysts and researchers, and/or workshops with stakeholders and decision-makers to develop qualitative scenarios (Fig. 2). Once identified by workshop participants, key issues and drivers directed further data acquisition from targeted information sources (e.g., climate, environmental indicators used by municipalities) and defined inputs and structural details regarding local system dynamics, future and historic trends, as well as potential adaptations and missing or required policies. A core working group coordinated the overall process, including identifying technical and subject-matter expert teams, managing analysis, and reporting.

This information formed the basis for delineating what would be included in the model and how regional decisions would be made so as to reflect current and future conditions (where future was defined as the next 25 years after the start of the project; first workshop). The methodological steps to develop the scenarios used available information on key future drivers and trends derived from regional projections (Ontario Ministry of Finance 2014), global and national scenarios (von Lampe et al. 2014; Willenbockel 2011; Chiotti and Levander 2008), and stakeholders' inputs and direction. The content of all scenarios was ultimately defined by participants during workshops. The key methodological steps used to establish the scenarios were based on a number of recent sources, including those of Volkery et al. (2006), Carlsen et al. (2012), and Bizikova et al. (2014). A total of five scenarios were defined for the region. One of them, the 'business as usual' (BAU) scenario, representing the status quo (using current trends), served as the reference for evaluating relative benefits and risks under the alternative future scenarios (second workshop). Participants then defined four alternative future scenarios that represented the range of potential futures likely given the key drivers affecting the region. In order to explore potential challenges and opportunities, these 
Fig. 2 Scenario development framework for mainstreaming adaptation to climate change into regional planning considerations at the landscape level

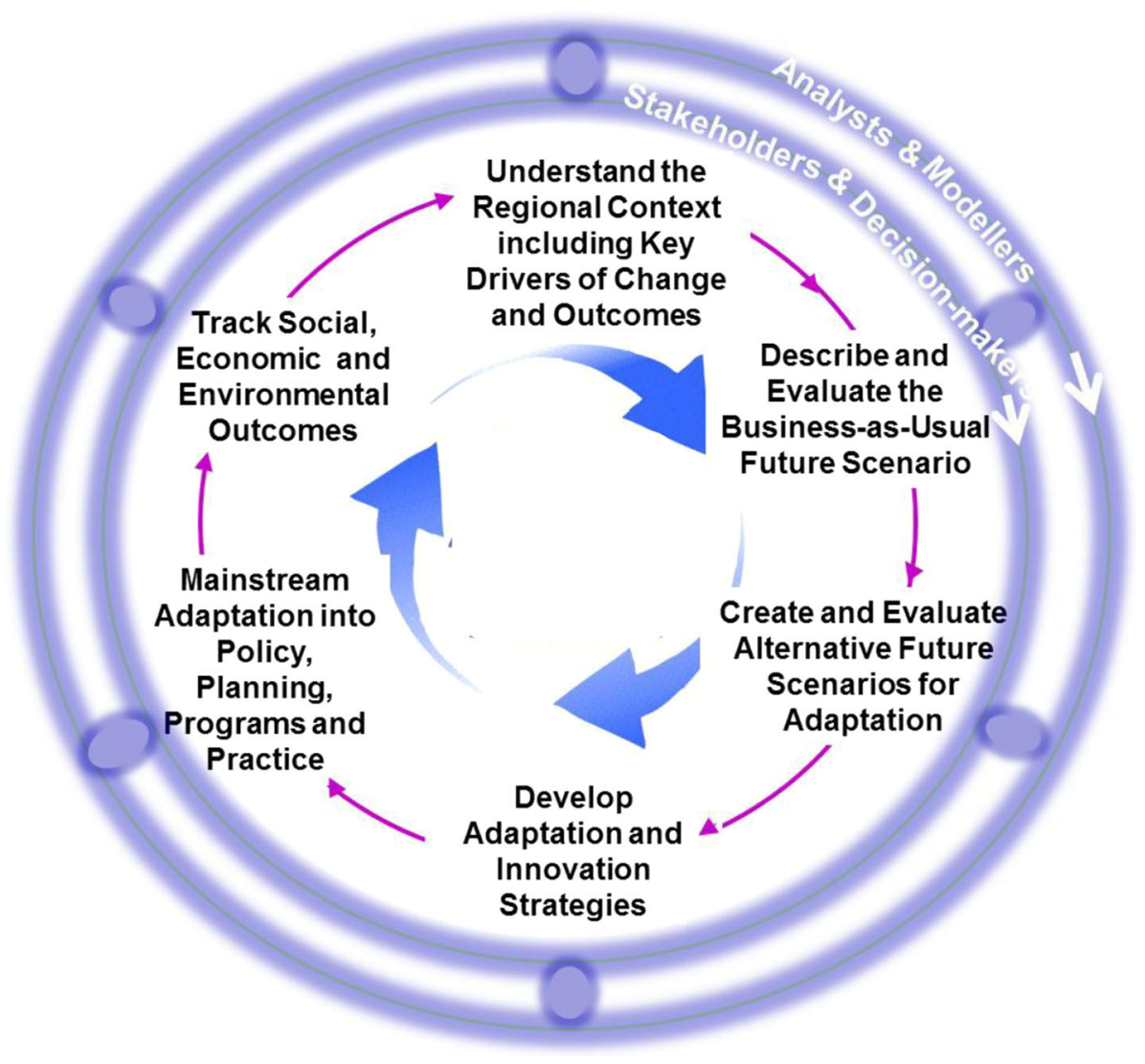

qualitative scenarios were quantified so as to reflect future climate, agricultural production, changes in crops and crop yields and agricultural and environmental management practices over time to be calculated and represented visually (Bolte et al. 2006; Guzy et al. 2008; Hulse et al. 2009). The quantified scenarios were reviewed and validated by the stakeholders during the third workshop. These detailed overview of the methodological approach used to quantify the scenarios is described in the supplementary material.

A 25-year time span was selected for the scenario development because it was long enough to detect patterns of change of interest while being short enough to allow decision-makers to consider how to implement different adaptation strategies, policies, or practices. Working with these developed scenarios, the fourth and final workshop focused on considering the relative trade-offs within each scenario and using these to create a comprehensive set of regional adaptation needs and actions. It is important to note that the process of formalizing adaptations into actual strategies and mainstreaming actions into existing policies/ programs requires longer time horizons than the duration of this study and was not considered. However, models and outputs from this work were designed to address specific information gaps identified by regional authorities participating in this scenario process.

\section{Results}

Describing key drivers for use in the scenarios

Drivers influencing future outcomes can be broadly characterized as either unpredictable factors (e.g., not knowing what people will do); factors for which there is limited knowledge or understanding of feedbacks and interactions; and factors for which there is missing or incomplete data/information (structural and value uncertainty; Bizikova et al. 2011). The scenario process identified common priorities and challenges. There was broad agreement among stakeholders in the need for sustainable practices as a priority. In particular, participants ranked protecting and managing water and aquatic systems in light of the key drivers as a high priority. As such, environmental and economic drivers of policy were considered in the context of this objective. Climate change was considered differently than social and environmental priorities (water, wildlife, living wage, health care, agricultural and other land use practices, etc.,), being viewed as an overarching influence that would affect all other priorities, including land use, land management (e.g., pests and disease, infrastructure) and human health (Fig. 3). 


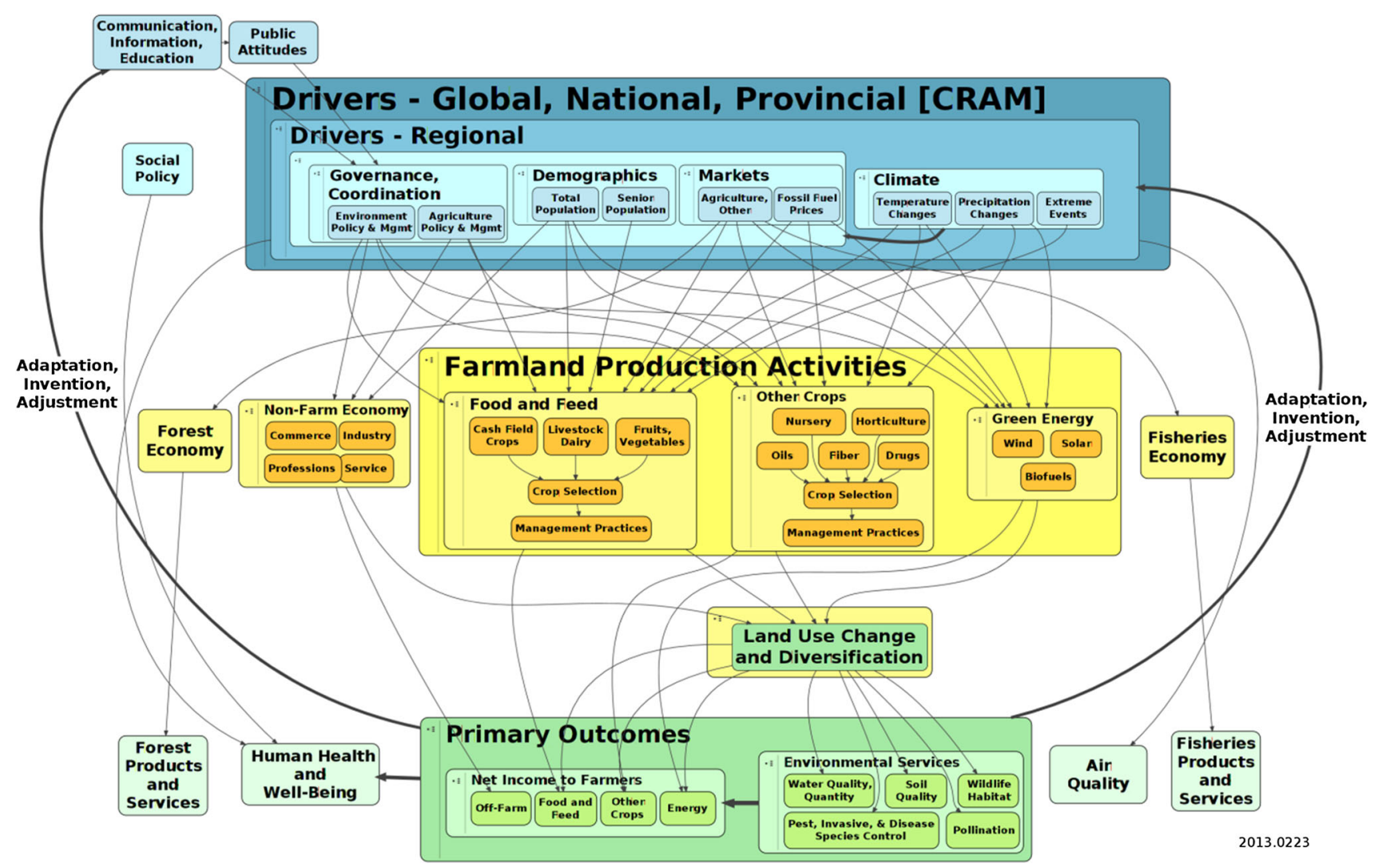

Fig. 3 Systems diagram showing key drivers and their pathways of influence (defined through stakeholder input during scenario process)

The shared perspective on drivers and priorities translated into a common view regarding drivers with the highest levels of uncertainty and highest potential impacts (Fig. 3). Climate change was unequivocally identified as one of the most critical 'unknowns' for operational and strategic planning, making it the overriding driver and focus of this work. There was also high concordance regarding key 'uncertainties' for the region, viewed as those expected to have the greatest influence on how sectoral activities were likely to change in the future. These included unpredictable drivers, such as those under external influences (e.g., energy prices) as well as drivers that are difficult to predict due to a lack of information (global market changes: economics, profitability, and market variability, and governance: local and multi-level).

\section{Overview of the developed future scenarios}

Socioeconomic considerations dominated all scenarios. Climate information framed discussions around how changing climatic conditions are expected to affect the region (relative to BAU). Under the BAU future, there was an implicit assumption that the food industry and international crises would be key drivers of local demand. This presumes a continued reliance on exports generally, with some increase in high-value products (e.g., meat and organic products), and a predicted (with high confidence under the government at the time) lessening of regulations, and reductions in the influence of marketing boards and supply management systems.

Stakeholders then considered how the various drivers influenced the ways the region might be developed. Economic drivers were viewed as the most important factors influencing land use decisions, although the state of 'environmental features' (e.g., biodiversity, water, soils) was also considered a priority. In these views of the future, market influences were a key driver influencing both emerging and new opportunities. Alternatives to trade, on the other hand, such as 'green' or 'environmental' changes were seen as being principally driven through incentives such as new policies and supportive programs. In all scenarios, external (export-driven) demands for cash crops were seen as increasing at the expense of (local) subsistence and livestock crops (e.g., vegetable crops, silage, and pasture). Of all five scenarios (including BAU), only the 'Living Locally' scenario (LL) included climate change adaptations and environmental objectives as tools to specifically address resilience and local food security. In contrast, other scenarios were seen to be impacted by climate change although they were defined largely by more immediate economic concerns. 
The principal differences between the four alternative future scenarios were in the degree to which markets versus more centrally directed policies and regulations influenced decisions. However, each scenario was seen as offering opportunities to create resilience through coordinated action by relevant stakeholders. Coordination was seen as important by participants, since increasing global competition, climate change impacts, and diminishing public funds make the most likely way of realizing future opportunities (and adaptation) through collective planning. The most intensive growth scenario 'Global Market' (GM) had the least engagement by local 'actors' of the four. GM represented a future in which choices about land use and growth are directed by (largely) external influences from global markets, which creates viable large-scale production but limited opportunity for local and regional governments to influence or manage adaptive strategies at the scale at which impacts of climate change are expected. The Bioeconomy (BE) future had similarities to the GM; however, changes were largely directed by regionally driven interest in exploring opportunities for new local industry and job opportunities. The remaining two scenarios, Greening Agriculture (GA) and LL futures, while also heavily driven by economics, placed greater emphasis on centrally coordinated regional planning. As such, these were viewed as enhancing resilience to climate change impacts through the introduction of proactive regulations to address ongoing and emerging issues. Only GA and LL futures provide a means for mainstreaming climate change adaptation into policy and planning processes.

Stakeholders used the scenario process to define futures that allowed them to emphasize core differences in pathways of decision-making while remaining plausible. For instance, local small-scale production was considered independently of large farming operations in the model, which allowed the relative performance of each to be considered under the different potential futures. So, while GM was beneficial for larger farms, it reduced the diversity of farms across the region (Table 1). In this example, this distinction allowed challenges and adaptation needs to be considered relative to the size of a farming operation (where the cost-benefit ratios will differ). The distinct storylines also allowed comparison of the robustness of different development pathways and objectives. For example, the scenario directed at building a bioeconomy outlined specific opportunities for the region to become a leader in producing new agricultural products, attracting innovators and investors (i.e., resources), and improving regional information flows through expanded collaborations among local governments and universities. The use of storylines also fostered discussions of what would be required to put each development pathway into practice, including strategic discussions about the importance of securing sustained commitments from key agencies and sectoral representatives beyond agriculture. In practice, the four discrete scenarios contributed to a shared understanding of benefits, opportunities, and risks associated with different trajectories of change.

\section{Challenges, opportunities, and common regional objectives}

Key challenges and opportunities stemming from the four scenarios are summarized in Table 2. Despite the relatively broad range of stakeholders represented within this study, certain challenges could not be explored in detail due to a lack of required expertise (e.g., forestry, fisheries, public health and transportation). Although adaptive planning was the focus of our process, discussions about the future focused primarily on addressing the more immediate priorities and challenges facing the region (i.e., local economics and energy markets) rather than the less well-defined and more distant impacts of climate change. Climate was factored in as an overarching and unpredictable influence on how current choices will influence the future physical and socioeconomic environment. As such, climate extremes were used to evaluate vulnerability of different economic trajectories. The scenarios were then useful to evaluate the economic and agri-environmental impacts of land use change under these trajectories, factoring in climate change.

Each scenario was strongly driven by global market opportunities with different pathways of regional response (and priorities). Both the BAU and GM future aim to meet increasing food demands on the open market; it is the degree of intensification that differs between the two. In both scenarios, economic impacts on business ventures were largely considered indirectly-in the context of extreme weather-since production failures are expected to be covered by insurance policies to some extent (more so for the larger farms that dominate these scenarios). Large farms are seen as having adequate financial resources to purchase insurance, whereas small- and medium-size farms may not, relying instead on other ways to stabilize income (Smit and Skinner 2002; Wall et al. 2011). Based on the stakeholders' views and experience, large farms were assumed to be more resilient in general, having access to new technologies, new varieties and the most current information to adjust their planted crops and management options based on climatic changes.

Trade agreements also drove farm size (larger) by favoring certain exports (cash crops) over others. As such, small farms were seen as disappearing unless special provisions for supportive policies and incentives existed to retain them on the landscape in the face of competition for agricultural land. Only two futures incorporated local policies and regulatory activities (GA and LL). In these 
Table 1 Overview of challenges identified by stakeholders under different regional futures in Eastern Ontario

\begin{tabular}{|c|c|c|c|c|c|c|c|c|}
\hline Scenario & $\begin{array}{l}\stackrel{0}{N} \\
\text { in } \\
\text { E } \\
\text { I }\end{array}$ & 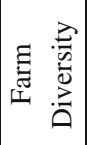 & 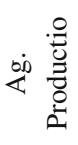 & (2) & 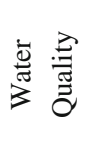 & 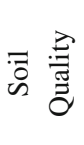 & 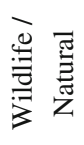 & Opportunities \\
\hline BAU & & & & & & & & $\begin{array}{l}\text { Maintain focus on export based } \\
\text { production. Crop choices in line } \\
\text { with current trends, targeting export } \\
\text { markets with a shift towards larger } \\
\text { farms; more farms have resources } \\
\text { to address adaptation. }\end{array}$ \\
\hline $\begin{array}{l}\text { Global } \\
\text { Markets }\end{array}$ & & & & & & & & $\begin{array}{l}\text { Intensification leading to } \\
\text { monoculture creates vulnerabilities } \\
\text { to catastrophic crop loss (e.g., pest, } \\
\text { drought). However, larger farms are } \\
\text { more resilient to impacts as they are } \\
\text { well resourced (including financial } \\
\text { resources for crop insurance). } \\
\text { Potential farm income is great, with } \\
\text { economic benefits extending to } \\
\text { other sectors. New farmers and } \\
\text { investors enter region. Immigration } \\
\text { introduces new farm practices. }\end{array}$ \\
\hline $\begin{array}{l}\text { Bio- } \\
\text { Economy }\end{array}$ & & & & & & & & $\begin{array}{l}\text { New crops introduced. A research } \\
\text { and development focus opens new } \\
\text { industry, commercialization, and } \\
\text { markets. }\end{array}$ \\
\hline $\begin{array}{l}\text { Greening } \\
\text { Ag. }\end{array}$ & & & & & & & & $\begin{array}{l}\text { Focus is on improving agricultural } \\
\text { performance and mitigating water } \\
\text { quality concerns. BAU with some } \\
\text { 'green fixes'. New policy and } \\
\text { private initiatives create } \\
\text { opportunities for better land } \\
\text { management practices in the region. }\end{array}$ \\
\hline $\begin{array}{l}\text { Living } \\
\text { Locally }\end{array}$ & & & & & & & & $\begin{array}{l}\text { Actively retain small farms with } \\
\text { targeted policy and programs. } \\
\text { Wildlife and environmental states } \\
\text { benefit from targeted placement of } \\
\text { small farms within watersheds. } \\
\text { Opportunities for environmental } \\
\text { service delivery through small } \\
\text { farms. Diversification increases as } \\
\text { does supply to local markets. } \\
\text { Policies creating environmental } \\
\text { benefits (e.g., wildlife, water } \\
\text { quality) are considered. }\end{array}$ \\
\hline
\end{tabular}

Arrows denote increase or decrease with size reflecting relative magnitude of a change relative to trends expected under BAU two, policies focused on encouraging local food production (market farms) and environmentally sensitive land management. This resulted in more structurally diversified landscapes that were less vulnerable to market and climate shocks. This was viewed by the stakeholders as an important issue, who regarded keeping pockets of small farms as an important characteristic of the landscape to maintain in the future. It was also recognized that policies would be needed to retain diversified landscapes, since extreme weather events would be problematic for such small farms-unless new forms of crop and livestock insurance protection were introduced for such diversified farmers.

Environmental performance was an important measure for the scenarios. Stakeholders considered how land use and management practices would impact water, wildlife, soil, and other environmental features, as well as how resilient each scenario would be future extreme climate events. Agricultural intensification was seen as having detrimental impacts on performance. Overall, the most intensive futures were seen as carrying more significant impacts on the environment, largely through increased farm size intruding into previously naturalized areas. Intensive agricultural practices combined with population growth were projected to further reduce natural habitat, exacerbating declines in some species at risk. On the other hand, in some scenarios wildlife species were seen to benefit from the expansion of farmland by adding new habitat or perennial cover in the form of bioproduct crops. In the GA and BE futures, the introduction of perennial crops actually benefited wildlife by creating new habitat and offsetting conversion of pasture to cash crops. As such, 
Table 2 Overview of adaptations identified as important in Eastern Ontario at the different stages of the framework implementation

$\begin{array}{lll}\begin{array}{l}\text { Prior to scenario } \\ \text { development process }\end{array} & \begin{array}{l}\text { Based on the } \\ \text { qualitative } \\ \text { scenarios }\end{array} & \begin{array}{l}\text { Based on the } \\ \text { quantified } \\ \text { scenarios }\end{array}\end{array}$

Farm-level actions

Tools for land owner to respond to CC-trade policy, remote/GIS data to help $\mathrm{X}$ $\mathrm{X}$ agriculture, weather prediction

Review of habitat allocations (especially species at risk) and this could mean $\mathrm{X}$ changes in land use/agriculture management practices and land allocations

Methods of more efficient water delivery/irrigation

$\mathrm{X}$

Stronger regulation on shoreline protection, land use change that increases $\mathrm{X}$ runoff

Source water protection measures in areas prone to water contamination, nutrient inflows especially in areas that could be affected by heavy rainfall (may limit expansion of operations in these areas)

Crop-breeding programs

Economic and technology

New technology — adoption of specific land management technologies to address risk and change (e.g., land use, rotations, pest management)

New storage and processing technologies to fit better to a new crops and market needs

New approaches to marketing - to reach out to new markets, consumers, whole-sellers/grocery chains

New crop insurance to manage risks

Alternative modes of insurance for smaller and larger farms

New business models/longer contracts

Support for maintaining ecosystem goods and services

Erosion protection measures in areas prone to erosion to reduce impacts of heavy rainfall

Plant breeding — access moisture, dry weather

Improved infrastructure-water retention, improved drainage, irrigation in place (when needed-availability issue)

Incentivize rather than regulate-payment for ecosystem services for small farmers

Awareness and education

Framing more as a support for rural life/lifestyle rather than CC adaptation; rural revitalization (mainstreaming adaptation)

New technology, outreach and education

Encouraging cultural shifts both in the farming community and between policy-makers

\section{Providing tools and information}

Improving data availability and sharing between the communities and also ensuring that the data are regularly updated

Developing tools for decision-makers and farmers to plan for climate change impacts

Developing plans and support systems to implement new agricultural opportunities-biomass and related marketing and processing systems, local markets development, etc.,

Transition management and mitigation plans to address potential spread of forest pests

Investment into innovation-biotechnology
X

X

X

$\mathrm{X}$

X

X

X

X

X

$\mathrm{X}$

X

X

X

X

X

X

X

X

X

X

X

X

X

X

X

X

X

X

X 
both protecting existing natural areas through regulatory and incentive actions and creating new habitat were seen as important.

The greatest impacts of extreme weather were considered to included agricultural (crop failure, infrastructure damage) and social- and health-related impacts (e.g., power outages, road closures, morbidity), many of which were high concern for the participants regardless of their expertise. The broad impacts of floods and droughts to the agricultural economy were also considered in view of direct impacts (crop and livestock mortality) and indirect impacts (pest outbreaks or disease), with increasing farm size seen as increasing environmental challenges (e.g., runoff and water contamination by chemical pesticides, fertilizer, and erosional forces). Implications of other climate considerations, such as trends toward milder winter temperatures, changing rainfall patterns and other shifts were less clear. The GA and LL future, which explicitly set out to mitigate climate change impacts, were evaluated as the best performers.

\section{Selecting adaptation priorities and actions in the context of the scenarios}

Based on the priorities and challenges identified through the scenario process, stakeholders were asked to identify the three most important considerations for changing management practices, policy and adaptation to address a changing climate (Table 2). The considerations were numerous and the ensuing discussion led to a list of specific multi-scale actions and focused participants on defining strategic adaptation options to address constraints and opportunities in implementing these actions. Under each of the future scenarios, discussions provided new insights about future uncertainties that translated into the addition of new adaptation actions relative to those originally considered. Of particular note was an increase in the number of collaborative and cross-sectoral adaptive priorities, such as education (technology and outreach) and more mechanisms to protect regional ecosystem goods and services (e.g., tools and information, policy and programs).

Given that management practices and decisions about how to use land and resources were seen as factors that would increase regional vulnerability to climate change, developing suites of adaptation tools to encourage change was important under all scenarios. These included, for example, expanded or new funding and programs to enable farm-level adoption of alternative technologies and practices, economic and technological resource support to better understand and manage future risks and challenges, and mechanisms (tools and information) to encourage better communication among sectors and stakeholders. Integrated landscape plans were core aspects of the LL and
GA scenarios, both of which required a series of fundamental changes in policies to influence what would be done and where.

\section{Discussion}

In North America, climate change adaptation planning to date has not occurred at the national level, but in incremental applications at local and regional scales (IPCC 2014). Recognizing the need for more integrated adaptation tools in Canada, we set out to test a model that focuses on shared priorities within a common geographic area rather than on a disciplinary basis. The idea is that a mixture of regional stakeholders would benefit from a forum that enabled them to discuss and align their various regional priorities and prioritize critical adaptation options by identifying specific actions at local (farm-level) and regional scales simultaneously (Mahmoud et al. 2009; Waldick 2010). In this study, we found that the suites of adaptive priorities both expanded and shifted during the course of the scenario development process from lists that initially described more immediate and individual-scale actions, such as improving irrigation systems on farm, to actions of overall regional benefit that rely on greater coordination.

Regional planning communities also need strategies to implement adaptive actions. The framework and resulting scenarios were formulated by stakeholder priorities and shared objectives. By considering a number of plausible scenarios, this process emphasized the reality that economic drivers-such as market prices and trade agreements-are likely to remain a major influence in the region. Since these drivers are outside the influence of local planners, this also reinforced the importance of government and industry involvement to establish sectoral incentives or supportive programs to fully address local adaptation needs. The process of developing scenarios better equips stakeholders by helping to focus on the most critical drivers and key pathways of local and regional influence. This includes operational actions as well as identifying appropriate information and data sources (including expertise) to better evaluate impacts and pathways of effect. Interestingly, tools and information emerged as important for adaptation planning over the course of using the framework. Compared to other studies (Carlsen et al. 2012), this study made heavy use of already available information and data, but it was still challenged in integrating information to answer key questions about risks and future trends. Multi-disciplinary teams familiar with the regional datasets, issues, and priorities can reduce some of these demands, by contributing insights and context on an as-needed basis as part of an overall regional planning process. 
In contrast to other agricultural studies (Olesen et al. 2011; Öborn et al. 2013), this study considered both climate change impacts and regional factors, by incorporating information regarding major economic, environmental and social drivers, both external and internal, of importance to the region. By focusing on plausible trajectories, stakeholders were able to explore a wide possible range of changes, including what might be required for their implementation. This allowed new opportunities to be considered (e.g., bioeconomy focus for the region), highlighted the potential importance of centrally coordinated regional planning, and emphasized the need for overarching (funding) programs to address externalities through the use of incentives and other supportive programs. It also divided actions into those that could be addressed regionally from those that could not. In this way, including alternative pathways to what currently exists within the region (e.g., bioeconomy and local markets), stakeholders were able to explore ways the region could (collectively) develop in the future to better address potential risks under climate change.

One of the most striking results from this work is the extent to which there was high congruence regarding the key drivers that would have the greatest impact on the region in the future, despite the diverse range of priorities represented by stakeholders from different sectors and interests. The existence of these shared areas of concernin this case, consequences of the key drivers on the region-allowed stakeholders to focus on exploring common regional responses within the context of their more immediate priorities (Carlsen et al. 2012). This is reflected in the identification of new sets of adaptation priorities that require more coordination and engagement to design and implement among the various responsible authorities (e.g., economic and technological, education and information needs).

In this context, our outcomes highlight the importance of moving toward strategic adaptation priorities at the regional level. Interestingly, the most specific adaptation actions identified-directed support for adopting biotechnology, new crop-breeding programs and incentives for environmentally sensitive practice change-require considerable coordination with jurisdictional authorities at different level of governments to implement. Such adaptation action at the regional level would require more coordination among sectoral planners to create and deliver responses through use of appropriate mixes of incentives, training, information, new tools, and shared resources (i.e., public goods; Smit and Skinner 2002; Anton et al. 2011, 2013; Anwar et al. 2013). Planning processes involving high uncertainty will necessarily require the mainstreaming of climate considerations into planning be an ongoing process, involving continued interaction between regional stakeholders and agencies so that plans be developed, implemented, and revisited as new information and priorities are identified.

\section{Concluding remarks: future research and policy needs}

The use of this adaptation framework identified several policy and research needs to advance effective adaptation actions. An important starting point is improving the flow and sharing of information among policy, practitioner, and research communities. On the policy side, this includes creating mechanisms to facilitate information flows around key drivers and multi-disciplinary analysis (e.g., through shared databases, facilitated engagement processes, etc.,). Given the importance of external factors in driving local land use decisions, government and sectoral programs are likely to be key to ensuring local capacity needs are met. Also important will be research that looks at ways to coordinate locally focused (e.g., farm-scale) adaptations so that they complement regionallevel actions and priorities. Ideally, the goal would be to identify pathways to improve the economic, social and environmental performance through coordinated regional actions that reduce overall vulnerability to climate change and identify appropriate sets of indicators and performance measures to track the effectiveness of local adaptations at larger scales.

Acknowledgments This research was supported by research funding through Agriculture and Agri-Food Canada. The authors wish to thank all participants, students, regional and local experts, and science and technical advisors who contributed time, helpful criticism and knowledge to the scenario and analytical parts of the work.

Open Access This article is distributed under the terms of the Creative Commons Attribution 4.0 International License (http://crea tivecommons.org/licenses/by/4.0/), which permits unrestricted use, distribution, and reproduction in any medium, provided you give appropriate credit to the original author(s) and the source, provide a link to the Creative Commons license, and indicate if changes were made.

\section{References}

Adger WN, Arnell NW, Tompkins EL (2005) Successful adaptation to climate change across scales. Glob Environ Change 15(2):77-86. doi:10.1016/j.gloenvcha.2004.12.005

Antón J, Kimura S, Martini R (2011) Risk management in agriculture in Canada (40) OECD Publishing. doi: 10.1787/18156797

Antón J, Cattaneo A, Kimura S, Lankoski J (2013) Agricultural risk management policies under climate uncertainty. Glob Environ Change 23(6):1726-1736

Anwar MR, Li Liu D, Macadam I, Li Liu D, Macadam I, Kelly G (2013) Adapting agriculture to climate change: a review. Theor 
Appl Climatol 113(1-2):225-245. doi:10.1007/s00704-0120780-1

Atkinson R, Flint J (2001) Accessing hidden and hard-to-reach populations: snowball research strategies. Social research UPDATE. Department of Sociology, University of Surrey, Guildford, p 4, http://sru.soc.surrey.ac.uk/SRU33.pdf

Baez JE, Kronick D, Mason AD (2013) Rural households in a changing climate. World Bank Res Obs 28(2):267-289. doi:10. 1093/wbro/lks008

Biesbroek GR, Swart RJ, Carter TR, Cowan C, Henrichs T, Mela H, Morecroft MD, Rey D (2011) Europe adapts to climate change: comparing national adaptation strategies. Global Environ Change 20:440-450

Bizikova L, Burch S, Shaw A, Sheppard S, Robinson J (2011) Uncertainty and integrated responses to climate change. In: Gramelsberger G, Feichter J (eds) Climate change and policy: the calculability of climate change and the challenge of uncertainty, Springer, pp $171-191$

Bizikova L, Pinter L, Tubiello FN (2014) Normative scenario approach: a vehicle to connect adaptation planning and development needs in developing countries. Reg Environ Change 15(7):1433-1446. doi:10.1007/s10113-014-0705-xh

Bolte JP, Hulse DW, Gregory SV, Smith C (2006) Modeling biocomplexity: actors, landscapes and alternative futures. Environ Modell Softw 22(5):570-579. doi:10.1016/j.envsoft.2005.12. 033

Burke M, Dykema J, Lobell DB, Miguel E, Satyanath S (2015) Incorporating climate uncertainty into estimates of climate change impacts. Rev Econ Stat 97(2):461-471

Carlsen H, Dreborg KH, Wikman-Svahn HP (2012) Tailor-made scenario planning for local adaptation to climate change. Mitig Adapt Strat Global Chang 18(8):1239-1255. doi:10.1007/ s11027-012-9419-x

Carter TR, Jylha K, Perrels A, Fronzek S, Kankaanpää S (2005) FINADAPT scenarios for the 21 st century: alternative futures for considering adaptation to climate change in Finland. FINADAPT Working Paper 2, Finnish Environment Institute Mimeographs 332, Helsinki

Chiotti Q, Lavender B (2008) Ontario: From Impacts to Adaptation: Canada in a Changing Climate, Chapter 6. In: Lemmen DS, Warren FJ, Lacroix J, Bush E (eds). Ottawa, Government of Canada. pp 227-274. https://www.nrcan.gc.ca/environment/ resources/publications/impacts-adaptation/reports/assessments/ 2008/10253. Accessed 14 Apr 2015

Duinker PN, Greig LA (2007) Scenario analysis in environmental impact assessment: improving explorations of the future. Environ Impact Assess 27(3):206-219. doi:10.1016/j.eiar.2006.11. 001

Eilers W, MacKay R, Graham L, Lefebvre A (eds). 2010. Environmental Sustainability of Canadian Agriculture: Agri-Environmental Indicator Report Series: Report No. 3. Agriculture and Agri-Food Canada, Ottawa, Ontario, http://publications.gc.ca/ collections/collection_2011/agr/A22-201-2010-eng.pdf. Accessed 28 Dec 2015

Eriksen S, Aldunce P, Bahimipati CS, Martins RD, Molefe JI, Nhemachena C, O'brien K, Olorunfemi F, Park J, Sygna L, Ulsrud K (2011) When not every response to climate change is a good one: identifying principles for sustainable adaptation. Clim Dev 3(1):7-20. doi:10.3763/cdev.2010.0060

Fisher AC, Hanemann WM, Roberts MJ, Schlenker W (2012) The economic impacts of climate change: evidence from agricultural output and random fluctuations in weather comment. Am Econ Rev 102(7):3749-3760

Flitcroft K, Gillespie J, Salkeld G, Carter S, Trevena L (2011) Getting evidence into policy: the need for deliberative strategies? Soc Sci Med 72(7):1039-1046. doi:10.1016/j.socscimed.2011.01.034
Guzy, MR, Smith CL, Bolte JP, Hulse DW, Gregory SV (2008) Policy research using agent based modeling to assess future impacts of urban expansion into farmlands and forests. Ecol Soc 13(1):37. http://www.ecologyandsociety.org/vol13/iss1/art37/

Harrison PA, Holman IP, Cojocaru G, Kok K, Kontogianni A, Metzger MJ, Gramberger M (2013) Combining qualitative and quantitative understating for exploring cross-sectoral climate change impacts, adaptation and vulnerability in Europe. Reg Environ Change 13(4):761-780. doi:10.1007/s10113-012-0361$\mathrm{y}$

Howden MS, Soussana JF, Tubiello FN, Chhetri N, Dunlop M, Meinke H (2007) Adapting agriculture to climate change. Proc Natl Acad Sci 104(50):19691-19696. doi:10.1073/pnas. 0701890104

Hulse D, Branscomb A, Enright C, Bolte J (2009) Anticipating floodplain trajectories: a comparison of two alternative futures approaches. Landsc Ecol 24(8):1067-1090. doi:10.1007/s10980008-9255-2

International Food Policy Research Institute (2010) Food Security, Farming, and Climate Change to 2050: Scenarios, Results, Policy Options. IFPRI, Washington, DC, pp 155 Retrieved from: http://www.ifpri.org/sites/default/files/publications/rr172.pdf. Accessed 15 Apr 2015

IPCC (2012) Summary for Policymakers. In: Managing the risks of extreme events and disasters to advance climate change adaptation. Field CB, Barros V, Stocker TF, et al (eds) A Special Report of Working Groups I and II of the Intergovernmental Panel on Climate Change. Cambridge University Press, Cambridge, UK, and New York, NY, USA, pp 1-19

IPCC (2014) Summary for policymakers. In: Climate Change 2014: Impacts, Adaptation, and Vulnerability. Part A: Global and Sectoral Aspects. Contribution of Working Group II to the Fifth Assessment Report of the Intergovernmental Panel on Climate Change Field CB, Barros V, Mastranandrea MD, Mach KJ, Abdrabo MK, Adger N, Anokhin YA, Anisimov OA, Arent DJ, Barnett J, Burkett VR, (eds.) Cambridge University Press, Cambridge, United Kingdom and New York, NY, USA, pp. 1-32. https://www.ipcc.ch/pdf/assessment-report/ar4/wg1/ ar4-wg1-spm.pdf. Accessed 15 Apr 2015

Kharin VV, Zweirs FW (2005) Estimating extremes in transient climate change simulations. J Climate 18(8):1156-1173. doi:10. 1175/JCLI3320.1

Kirk DA, Lindsay KE, Brook RW (2011) Risk of agricultural practices and habitat change to farmland birds. Avian Conserv Ecol 6(1):5

Kulshreshtha S, Wheaton E, Brebbia CA, Popov V (2013) Climate change adaptation and food production in Canada: some research challenges. In Second International Conference on Food and Environment: The Quest for a Sustainable Future, Budapest, Hungary, 22-24 April 2013, pp 101-112. WIT Press

Mahmoud M, Liu Y, Hartmann H, Stewart S, Wagener T, Semmens D, Stewart R, Gupta H, Dominguez F, Hulse D, Letcher R, Rashleigh B, Smith C, Street R, Ticehurst J, Twery M, van Delden H, Waldick R, White D, Winter L (2009) A formal framework for scenario development in support of environmental decision-making. Environ Model Softw 24(7):798-808

Nelson GC, van der Mensbrugghe D, Ahammad H, Blanc E, Calvin K, Hasegawa T, Havlik P, Heyhoe E, Kyle P, Lotze-Campen H, Lampe M (2014) Agriculture and climate change in global scenarios: why don't the models agree Agr Econ 45(1):85-101. doi:10.1111/agec.12091

O'Brien K, Eriksen S, Nygaard L, Schjolden A (2007) Why different interpretations of vulnerability matter in climate change discourses. Clim Policy 7(1):73-88

Öborn I, Magnusson U, Bengtsson J, Vrede K, Fahlbeck E, Jensen ES, Westin C, Jansson T, Hedenus F, Lindholm Schulz H, 
Stenström M, Jansson B, Rydhmer L (2011) Five scenarios for 2050: conditions for agriculture and land use. Swedish Univ Agric Sci, Uppsala. ISBN 978-91-576-9032-6

Öborn I, Bengtsson J, Hedenus F, Rydhmer L, Stenström M, Vrede K, Westin C, Magnusson U (2013) Scenario development as a basis for formulating a research program on future agriculture: a methodological approach. Ambio 42(7):823-839

Olesen JE, Trnka M, Kersebaum KC, Skjelvag AO, Sequin B, Peltonen-Sainio P, Rossi F, Kozyra J, Micale F (2011) Impacts and adaptation of European crop production systems to climate change. Eur J Agron 34(2):96-112

Ontario Ministry of Agriculture, Food, and Rural Affairs (2015) Agrirecovery Assessment Summary. http://www.omafra.gov.on. ca/english/infores/releases/2013/011013-bg.htm. Accessed 15 Apr 2014

Ontario Ministry of Finance. 2014. Ontario Population Projections Update, 2010-2036. http://www.fin.gov.on.ca/en/economy/demo graphics/projections/projections2010-2036.pdf. Accessed 5 April 2014

Polasky S, Carpenter SR, Folke C, Keeler B (2011) Decision-making under great uncertainty: environmental management in an era of global change. Trends Ecol Evol 26(8):398-404. doi:10.1016/j. tree.2011.04.007

Qian B, Gameda S, de Jong R, Falloon P, Gornall J (2010a) Comparing scenarios of Canadian daily climate extremes derived using a weather generator. Climate Res 41:131-149. doi: $10.3354 / \mathrm{cr} 00845$

Qian B, Zhang X, Chen K, Feng Y, O'Brien T (2010b) Observed long-term trends for agroclimatic conditions in Canada. J Appl Meteorol Clim 49(4):604-618. doi:10.1175/2009JAMC2275.1

Reid S, Smit B, Caldwell W, Belliveau S (2007) Vulnerability and adaptation to climate risks in Ontario agriculture. Mitig Adapt Strat Global Chang 12(4):609-637. doi:10.1007/s11027-0069051-8

Rochette P, Belanger G, Castonguay Y, Bootsma A, Mongrain D (2004) Climate change and winter damage to fruit trees in eastern Canada. Can J Plant Science 84(4):1113-1125

Seo SN (2013) An essay on the impact of climate change on US agriculture: weather fluctuations, climatic shifts, and adaptation strategies. Clim Change 121(2):115-124

Shaw A, Sheppard S, Burch S, Flanders D, Wiek A, Carmichael J, Robinson J, Cohen S (2009) Making local futures tangiblesynthesizing, downscaling, and visualizing climate change scenarios for participatory capacity building. Glob Environ Change 19(4):447-463. doi:10.1016/j.gloenvcha.2009.04.002

Smit B, Skinner MW (2002) Adaptation options in agriculture to climate change: a typology. Mitig Adapt Strat Glob Change 7(1):85-114. doi:10.1023/a:1015862228270
Stirling A (2006) Analysis, participation and power justification and closure in participatory multi-criteria analysis. Land use policy 23(1):95-107. doi:10.1016/j.landusepol.2004.08.010

Thomalla F, Downing T, Spanger-Siegfried E, Han G, Rockstrom J (2006) Reducing hazard vulnerability: towards a common approach between disaster risk reduction and climate adaptation. Disasters 30:39-48. doi:10.1111/j.1467-9523.2006.00305.x

Tompkins EL, Few R, Brown K (2008) Scenario-based stakeholder engagement: incorporating stakeholders preferences into coastal planning for climate change. J Environ Manag 88(4):1580-1592. doi:10.1016/j.jenvman.2007.07.025

UKCIP (2011) Making progress: UKCIP and adaptation in the UK. UK Climate Impacts Programme, Oxford, UK

van Buuren A, Driessen P, Teisman G, van Rijswick M (2014) Toward legitimate governance strategies for climate adaptation in the Netherlands: combining insights from a legal, planning, and network perspective. Reg Environ Change 14(3):1021-1033. doi:10.1007/s10113-013-0448-0

Verburg PH, Schot PP, Dijst MJ, Veldkamp A (2004) Land use change modelling: current practice and research priorities. GeoJournal 61(4):309-324

Volkery A, Swanson D, Jacob K, Bregha F, Pinter L (2006) Coordination, Challenges, and Innovations in 19 National Sustainable Development Strategies. World Dev 34:2047-2063. doi:10.1016/j.worlddev.2006.03.003

von Lampe M, Willenbockel D, Ahammad H, Blanc E, Cai Y, Calvin K, Fujimori S, Hasegawa T, Havlik P, Heyhoe E, Kyle P (2014) Why do global long-term scenarios for agriculture differ? An overview of the AgMIP Global economic model intercomparison. Agr Econ 45(1):102-111. doi:10.1111/agec.12086

Waldick R (2010) The role of institutions in integrated management. Horizons 10(4):73-80

Wall E, Smit B, Wandel J (2011) Farming in a changing climate: agricultural adaptation in Canada. UBC Press, Vancouver

Willenbockel D (2011) Exploring Food Price Scenarios Towards 2030 with a Global Multi-Region Model. Institute of Development Studies at the University of Sussex, UK. https://www. oxfam.org/sites/www.oxfam.org/files/rr-exploring-food-pricescenarios-010611-en.pdf. Accessed 5 April 2015

Yusa A, Berry P, Cheng J, Ogden N, Bonsal B, Stewart R, Waldick R (2015) Climate change, drought and human health in Canada. Int J Environ Res Public Health 12(7):8359-8412. doi:10.3390/ ijerph120708359 